\title{
The Effect of Smart City Policy on Urban Haze Pollution in China: Empirical Evidence from a Quasi-Natural Experiment
}

\author{
Yanchao Feng1, Shilei Hu ${ }^{2 *}$ \\ ${ }^{1}$ Business School, Zhengzhou University, Zhengzhou 450001, China \\ ${ }^{2}$ School of Management, Harbin Institute of Technology, Harbin 150001, China
}

Received: 14 June 2021

Accepted: 6 November 2021

\begin{abstract}
Utilizing the panel data of 285 prefecture and above cities between 2003 and 2018, this study investigated the effect of smart city policy on urban haze pollution in China at national, regional, and city administrative rank levels by using the difference-in-differences (DID) model and the spatial difference-in-differences (SDID) model. Results show that, in general, smart city policy reduced urban haze pollution of pilot cities. Moreover, the results confirm the presence of spatial heterogeneity in the intensity of the pollution mitigation effect at regional and city administrative rank levels. Additionally, this study identifies the spatial spillover effect of smart city policy and provides empirical evidence of the coexistence of "beggar-thy-neighbor" effect and "demonstration effect", which indicates the difficulty of haze pollution control in the process of smart city construction and highlights the importance and necessity of top-level design and differentiated policies of smart cities. Finally, several meaningful implications and research avenues are outlined.
\end{abstract}

Keywords: spatial difference-in-differences, smart city policy, urban haze pollution, spatial heterogeneity

\section{Introduction}

Since the launch of the reform and opening up, China's economy has maintained a speed of moderateto-rapid growth for several decades [1]. However, with the characteristics of high investment and high pollution, the traditional extensive development model has resulted in some severe urban diseases, such as traffic congestion, inflated housing prices, urban land shortage, and especially environmental pollution, which

*e-mail: yiruodongchuan@163.com has drawn the attention of academics and policymakers [1-3]. To achieve sustainable urban development, new urbanism and smart growth movements began to flourish in the 1990s [4, 5]. Against this background, the concept of smart city began to take shape. Smart city refers to the city that could maximize desirable outputs with limited resource inputs by the use of information and communication technologies (ICTs) to improve urban services in multiple aspects including business, transportation, communication, water, energy and other urban systems $[3,6]$. Smart city is a new city pattern which integrates resources in a way that can provide better urban services on the basis of making full use of the ICTs [3]. 
The first "smart city" initiative originated from the "Smarter Planet" project proposed by IBM Corporation in 2008, which treated smart city as the breakthrough point of smart earth [7]. Currently, many countries are attempting to create or develop smart cities and smart city has become a major policy priority in many countries [8]. For instance, many smart cityrelated policies and projects have been carried out in various countries around the world (e.g., the "Digital Britain" plan in UK, the Galway Bay "Smart Bay" project in Ireland, the "T-City" project in Germany, the "I-Japan" strategy in Japan, and the "U-Korea" strategy in South Korea [9-11]).

Following the wave of smart city construction, the Chinese government also devoted substantial efforts to develop smart cities to achieve the goal of sustainable and high-quality development in the long run. The smart city concept was initially introduced in China in 2010 [12]. Subsequently, the Chinese government formally proposed the smart city construction plan in its national policy in 2012 [9]. The development of smart city was written into the "2015 Report on the Government Work" as the future development direction for Chinese cities [3].

With the development of smart city construction practice around the world, increased academic attention has been paid to smart cities [13]. Smart cities are considered as a new way of thinking about urban space and future development goals [14], which is distinct from the traditional urban governance modes by its characteristics of thorough perception, deep interconnection, and intelligent applications [9]. Scholars believe that smart cities could be both a new engine of high-quality economic growth and the ideal solution to the environmental challenges of rapid urbanization $[15,16]$. That is, smart cities provide new ways to solve urban diseases through social governance reform and technological innovation and development [9]. Under such circumstance, an important question arises: have smart city policy (SCP) initiatives in cities around the world effectively reduced urban haze pollution? So far, the research on smart city is growing, owing to new advances of smart city practice across the world. For instance, Yu and Zhang (2019) investigated the effect of SCP on energy efficiency in China [13]. They found that there existed significant regional heterogeneity across cities, although the SCP exerted a significant positive effect on energy efficiency in general [13]. Yao et al. (2020) examined the impact of SCP on eco-efficiency, and revealed that, on the whole, the smart city construction significantly improves the eco-efficiency [17]. Guo et al. (2020) explored the effect of the implementation of SCP on urban traffic congestion, which showed that the smart city construction has significantly reduced the degree of urban traffic congestion [9]. Xu et al. (2020) analyzed the causal effects of SCP on urban innovation, and found that SCP in China positively and significantly impacts urban innovation [18]. Qian et al. (2021) studied the impact of SCP on economic green growth and showed that the establishment of smart cities has significantly promoted the green growth of the Chinese economy [19].

Through the above literature review, it can be seen that the implementation of SCP plays a positive role in alleviating urban traffic congestion, and promoting urban energy efficiency, urban eco-efficiency, economic green growth, and urban innovation. However, few studies empirically examined the link between SCP and environmental pollution.

To answer the aforementioned question, it is necessary to conduct empirical researches in various countries. To this end, the potential marginal contributions of this paper can be listed as follows: First, to the best of our knowledge, this is the first empirical research that comprehensively investigates the direct and indirect effects of SCP on urban haze pollution in China at national, regional, and city administrative rank levels by treating China's SCP as a quasi-natural experiment and adopting the DID and SDID models. Hence, this study provides empirical support for the argument that smart cities could be the ideal solution to the environmental challenges of rapid urbanization [15] and, hence, echoes the recent studies that have investigated the environmental effects of SCP $[1,17,20]$. The second contribution of this study is that it identified and verified the spatial heterogeneity of the effect of SCP on urban haze pollution and, hence, deepens the understanding of the environmental effects of SCP. This is especially important when considering that the Chinese government implemented an unbalanced development strategy at the early period of the reform and opening up and that cities in China have different administrative ranks (e.g., centrally administrated municipalities, cities designated in the state plan, provincial capitals, and sub-provincial cities) and levels of power and autonomy [21, 22]. Third, through scientific research methods, this study identifies the spatial spillover effect of SCP on urban haze pollution, which offers empirical support for establishing a regional environmental joint governance system. Last but not least, this study expands the boundary of the research topic on the effect of smart city, offering enlightening implications for smart city construction and urban haze pollution control in other emerging economies.

To sum up, this study aims to investigate the environmental effect of SCP under the Chinese scenario. Specifically, this study uses the smart city pilot in China as a public policy experiment to analyze the impact of the implementation of SCP on the haze pollution of pilot cities and their neighbouring and non-adjacent cities. Research conclusions of the paper provide new empirical evidence on the effect of SCP. 


\section{Materials and Methods}

\section{Data Source}

Referring to the information delivered by the Ministry of Housing and Urban-Rural Development (MOHURD) of China, the first, second, and third national lists of smart-city pilot project were announced on January, 2013, August, 2013 and April, 2015, covering 90, 103 and 97 cities, respectively. Currently, a total of 290 cities have been selected as national smart-city pilot cities [23]. The national smart-city pilot projects in China were implemented at the levels of cities, counties and towns. That is, the 290 pilot cities includes prefecture-level and above cities, countrylevel cities and town-level cities. Since the statistical data of cities at the country-level and the town-level were difficult to collect [13], this study focused on the pilot cities that were prefecture-level and above cities. Meanwhile, to capture the effect of smart-city policy comprehensively, the prefecture-level cities that these country-level and town-level pilot cities belong to were also incorporated into the experiment group cities. Finally, a total of 164 prefecture-level and above cities were marked as the smart cities. In addition, the treated time was regarded as the current year if the national smart-city pilot list was delivered in the first half of the year, otherwise the next year.
As for the data source of dependent variable (haze pollution) of this study, the $\mathrm{PM}_{2.5}$ emission data were derived from the Atmospheric Composition Analysis Group that is led by Randall Martin at Dalhousie University. They estimated ground-level fine particulate matter $\left(\mathrm{PM}_{2.5}\right)$ total and compositional mass concentrations over China by combining Aerosol Optical Depth (AOD) retrievals from the NASA MODIS, MISR, and SeaWIFS instruments with the GEOSChem chemical transport model, and then calibrated them to regional ground-based observations of both total and com-positional mass using Geographically Weighted Regression (GWR) $[24,25]$. The data of control variables were collected from the China City Statistical Yearbook (2004-2019), and the China Urban Construction Statistical Yearbook (2004-2019).

The research samples were obtained according to the following criteria: (1) exclude the cities that were dismantled during the study period, such as Chaohu, Bijie and Tongren; (2) exclude the cities that were established during the study period, such as Haidong, Turpan and Sansa; (3) exclude the cities with severe data lose, such as Lhasa; (4) exclude the cities with data inaccessibility, such as Hong Kong, Macau and Taiwan. Finally, given the availability, continuity and comparability of data, this study adopted a panel data covering 285 prefecture-level and above cities during 2003-2018 as the research sample. Fig. 1 illustrates

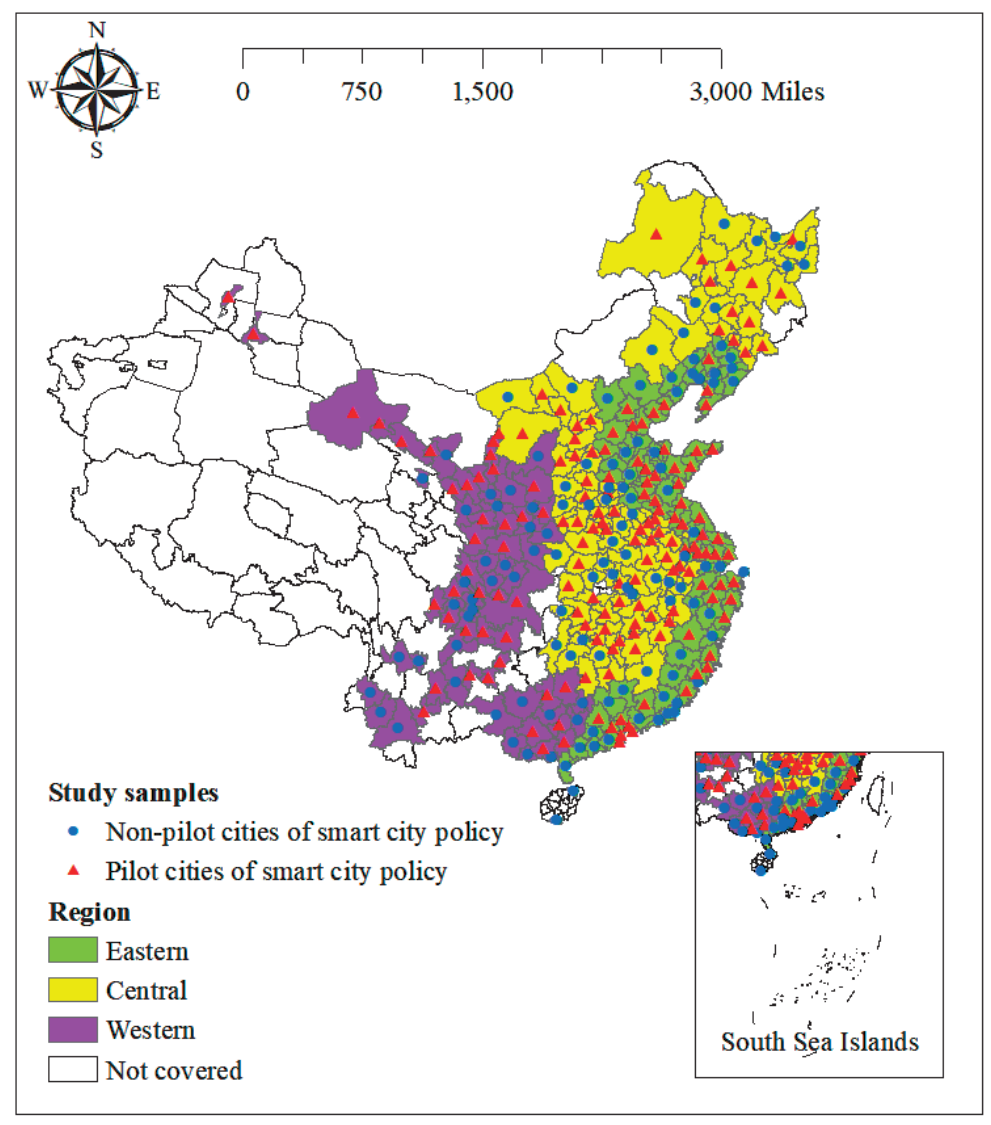

Fig.1. Geographical distribution of the study samples. 
the geographical distribution of sample cities, and also differentiates sample cities into groups: pilot cities of SCP, and non-pilot cities of SCP.

\section{Variable Specification}

(1) Dependent variable

Following prior studies [26, 27], the proxy indicator for haze pollution in this study is $\mathrm{PM}_{2.5}$ concentration $\left(P M_{25}\right)$

(2) Key explanatory variable

In this study, the key explanatory is SCP represented by $d_{u} \times d_{t}$, which takes the value 1 if a city conducted the national smart-city pilot in year $t$ and 0 in other cases. $d_{u}$ is the policy dummy variable, which equals to 1 if the corresponding city belongs to the list of national smart cities, and 0 otherwise. $d_{t}$ is the time dummy variable, which equals to 1 if the treated city has implemented national smart-city pilot policy, and 0 otherwise.

(3) Control variables

Referring to the current literature $[1,13,17$, 20], four control variables are incorporated into the regressive equations, including fiscal decentralization $(F D)$, industrial upgrading $(I U)$, urbanization rate $(U R)$, and foreign direct investment $(F D I)$. Specifically, fiscal decentralization $(F D)$ is represented by the proportion of financial expenditure to financial revenue, industrial upgrading $(I U)$ is represented by the proportion of the added value of the tertiary industry to the secondary industry, urbanization rate $(U R)$ is represented by the proportion of non-farm population to city's total population, foreign direct investment $(F D I)$ is represented by the proportion of foreign direct investment to GDP. The summary statistics are presented in Table 1.

\section{Econometric Model}

The DID model was employed to investigate the effect of SCP on urban haze pollution. Notably, to verify the average treatment effect and the dynamic marginal effect of SCP separately, this study adopted two different models, which are constructed as follows:

$$
y_{i t}^{*}=\alpha_{0}+\alpha_{1} d_{u} \times d_{t}+\alpha_{r} x_{i t}+\lambda_{i}+\mu_{t}+\varepsilon_{i t}(1)
$$

$$
\begin{gathered}
y_{i t}^{*}=\alpha_{0}+\alpha_{t} \sum_{t=2013}^{2018} d_{u} \times d_{t}+\alpha_{r} x_{i t} \\
+\lambda_{i}+\mu_{t}+\varepsilon_{i t}
\end{gathered}
$$

where $y_{i t}^{*}$ stands for the dependent variable of city $i$ in year $t ; \alpha_{0}$ is the constant term; $d_{u} \times d_{t}$ denotes the key explanatory variable; $\alpha_{1}$ and $\alpha_{t}$ are the coefficients of the key explanatory variable, which measures the average treatment effect and the dynamic marginal effect of the implementation of SCP on haze pollution respectively; $x_{i t}$ represents a vector of control variables; $\alpha_{r}$ denotes the coefficients of the control variables; $\lambda_{i}$ denotes the city-fixed effects to capture unobserved heterogeneity; $\mu_{t}$ denotes the year-fixed effects that control for temporal shocks; $\varepsilon_{i t}$ denotes the error term.

To ensure that the development trend of the treatment and control groups is parallel, this study adopted the parallel trend hypothesis test by adding the leads and lags of the initial dummy of SCP, which was set as follows:

$$
\begin{gathered}
y_{i t=}^{*} \alpha_{0}+\sum_{m=1}^{3} \alpha_{m} d_{u} \times d_{t-m}+\sum_{n=0}^{5} \alpha_{n} d_{u} \\
\times d_{t+n}+\alpha_{r} x_{i t}+\lambda_{i}+\mu_{t}+\varepsilon_{i t}
\end{gathered}
$$

where $d_{t-m}$ denotes m-year lead; $\alpha_{m}$ denotes the coefficient of $d_{u} \times d_{t-m} ; d_{t+n}$ denotes n-year lag; $\alpha_{n}$ denotes the coefficient of $d_{u} \times d_{t+n}$. The meaning of other parameters is the same as defined in Eq. (2).

To test the direct and indirect effects of SCP on urban haze pollution in China, the SDID model was employed following Chagas et al. (2016) [28], and the model was set as follows:

$$
\begin{gathered}
y_{i t}^{*}=\alpha_{0}+\alpha_{1} d_{u} \times d_{t}+\alpha_{r} x_{i t}+\beta_{1} W_{T, T} D_{i t} \\
+\beta_{2} W_{N T, T} D_{i t}+\beta_{r} W x_{i t}+\lambda_{i}+\mu_{t}+\varepsilon_{i t}
\end{gathered}
$$

where $W_{T T} D_{i t}$ denotes the spatial spillover effects among the treated cities (pilot cities); $\beta_{1}$ denotes the spatial coefficient of $W_{T, T} D_{i t}$; $W_{N, T} D_{i t}$ denotes the spatial spillover effects on the untreated cities (non-pilot cities) neighboring the treated cities; $\beta_{2}$ denotes the spatial coefficient of $W_{N, T} D_{i t} ; W$ represents the spatial weight matrix adopted in this study (including the firstorder adjacency weight matrix and the spatial squared inverse distance weight matrix); $\beta_{r}$ denotes the spatial

Table 1. Summary statistics.

\begin{tabular}{|c|c|c|c|c|c|c|c|c|c|}
\hline \multirow{2}{*}{ Variables } & \multicolumn{3}{|c|}{ Total sample } & \multicolumn{3}{c|}{ Treatment group } & \multicolumn{3}{c|}{ Control group } \\
\cline { 2 - 11 } & Obs. & Mean & Std.Dev. & Obs. & Mean & Std.Dev. & Obs. & Mean & Std.Dev. \\
\hline$P M_{2.5}$ & 4560 & 0.385 & 0.165 & 2624 & 0.408 & 0.151 & 1936 & 0.354 & 0.178 \\
\hline FD & 4560 & 2.314 & 2.039 & 2624 & 2.039 & 1.961 & 1936 & 2.687 & 2.083 \\
\hline IU & 4560 & 0.894 & 0.507 & 2624 & 0.877 & 0.452 & 1936 & 0.918 & 0.572 \\
\hline UR & 4560 & 0.519 & 0.265 & 2624 & 0.543 & 0.263 & 1936 & 0.487 & 0.263 \\
\hline FDI & 4560 & 0.023 & 0.032 & 2624 & 0.025 & 0.027 & 1936 & 0.019 & 0.038 \\
\hline
\end{tabular}


coefficients of the four control variables. The meaning of other parameters are consistent with Eq. (2).

\section{Results and Discussion}

Baseline Regressive Results

Based on Eqs. (1) and (2), the effects of SCP on urban haze pollution in China at the national level are reported in Table 2. Specifically, the results of average treatment effect and dynamic marginal effect are listed in columns (1)-(2) and columns (3)-(4), respectively. The coefficients of $d_{u} \times d_{t}$ are significantly negative in columns (1)-(2), which provides initial evidence that SCP has effectively reduced urban haze pollution in terms of average effect, no matter with or without the consideration of control variables. In particular, compared with non-pilot cities, SCP could reduce urban haze pollution by about 6\%-7\%. However, columns (3) and (4) show that the coefficients of $d_{u} \times d_{t}$ are significantly positive in 2013, positive but insignificant in 2014, and significantly negative after 2015, which indicates that the mitigation effect of SCP on urban haze pollution began to work after 2015 , no matter with or without the consideration of control variables, as viewed from the dynamic marginal effect perspective. Moreover, in general, the pollution reduction effect of SCP increases with time. That is, the longer the policy is implemented, the stronger its pollution reduction effect will be.

\section{Test of the Parallel Trend}

A critical identification assumption of the DID model is that the treatment group and the control group share a common change trend before the policy shocks (i.e., parallel trend assumption) [29]. Based on Eq. (3), the parallel trend test was conducted, and the corresponding coefficient diagram of key explanatory variable was reported in Fig. 2. It can be found that the coefficients of SCP on urban haze pollution are insignificant in the former three years and nearly equal to zero, indicating that there is no significant difference between the pilot and non-pilot cities of SCP before 2013. Hence, the parallel trend assumption is satisfied

Table 2. Baseline regressive results at the national level.

\begin{tabular}{|c|c|c|c|c|}
\hline \multirow{2}{*}{ Variables } & \multicolumn{2}{|c|}{ Average treatment effect } & \multicolumn{2}{|c|}{ Dynamic marginal effect } \\
\hline & (1) & (2) & (3) & (4) \\
\hline$d_{u} \times d_{t}$ & $\begin{array}{c}-6.643 * * * \\
(-22.429)\end{array}$ & $\begin{array}{c}-5.981 * * * \\
(-20.113)\end{array}$ & & \\
\hline$d_{u} \times d_{2013}$ & & & $\begin{array}{c}2.742 * * * \\
(3.191)\end{array}$ & $\begin{array}{l}1.791^{* *} \\
(2.156)\end{array}$ \\
\hline$d_{u} \times d_{2014}$ & & & $\begin{array}{c}0.924 \\
(1.508)\end{array}$ & $\begin{array}{c}0.045 \\
(0.076)\end{array}$ \\
\hline$d_{u} \times d_{2015}$ & & & $\begin{array}{c}-4.028 * * * \\
(-7.403)\end{array}$ & $\begin{array}{c}-4.579 * * * \\
(-8.608)\end{array}$ \\
\hline$d_{u} \times d_{2016}$ & & & $\begin{array}{c}-8.624 * * * \\
(-15.850)\end{array}$ & $\begin{array}{c}-8.894 * * * \\
(-16.619)\end{array}$ \\
\hline$d_{u} \times d_{2017}$ & & & $\begin{array}{c}-9.662 * * * \\
(-17.758)\end{array}$ & $\begin{array}{c}-7.850 * * * \\
(-14.360)\end{array}$ \\
\hline$d_{u} \times d_{2018}$ & & & $\begin{array}{c}-13.473 * * * \\
(-24.762)\end{array}$ & $\begin{array}{c}-11.429 * * * \\
(-20.755)\end{array}$ \\
\hline FD & & $\begin{array}{c}0.060 \\
(0.798)\end{array}$ & & $\begin{array}{c}0.073 \\
(1.006)\end{array}$ \\
\hline IU & & $\begin{array}{c}-3.541^{* * * *} \\
(-10.782)\end{array}$ & & $\begin{array}{c}-2.444 * * * \\
(-7.581)\end{array}$ \\
\hline UR & & $\begin{array}{c}8.811 * * * \\
(17.302)\end{array}$ & & $\begin{array}{c}7.627 * * * \\
(15.267)\end{array}$ \\
\hline FDI & & $\begin{array}{l}6.625^{*} \\
(1.721)\end{array}$ & & $\begin{array}{c}5.792 \\
(1.554)\end{array}$ \\
\hline Constant & $\begin{array}{c}44.269^{* * *} * \\
(374.262)\end{array}$ & $\begin{array}{c}42.450 * * * \\
(90.443)\end{array}$ & $\begin{array}{c}44.253^{* * *} \\
(396.452)\end{array}$ & $\begin{array}{c}42.109^{* * *} \\
(93.179)\end{array}$ \\
\hline Observations & 4,560 & 4,560 & 4,560 & 4,560 \\
\hline R-squared & 0.105 & 0.202 & 0.204 & 0.263 \\
\hline
\end{tabular}

Notes: t-statistics in parentheses; $* * * \mathrm{p}<0.01,{ }^{*} \mathrm{p}<0.05,{ }^{*} \mathrm{p}<0.1$. The following tables have the same notes as in this table; to save space, they are no longer reported 


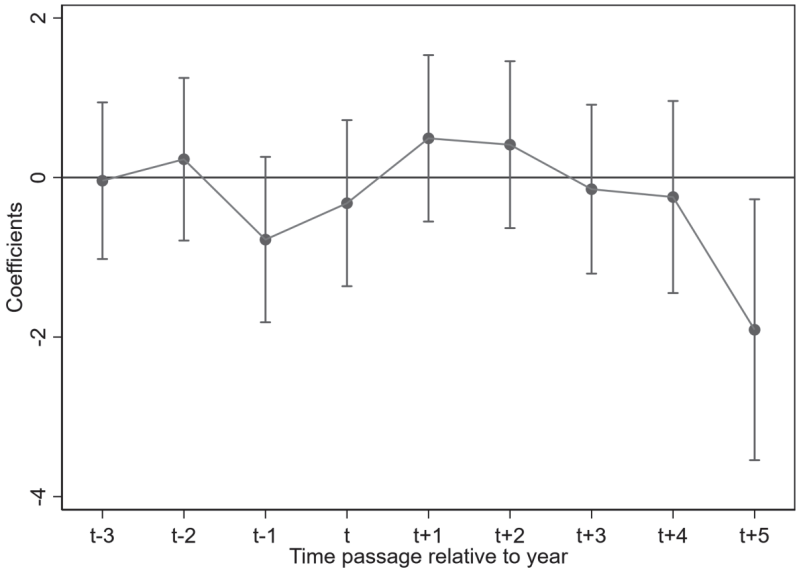

Fig. 2. Parallel trend analysis

here. However, the coefficients of SCP do not become significant until five years later, indicating a five-year lag in the effect of SCP on urban haze pollution.

\section{Placebo Test}

To eliminate the impact of the potential unobserved factors in the selection of pilot cities of SCP and verify the robustness of prior empirical results, this study conducted the placebo test. Specifically, 1000 times of random sampling among 285 cities were performed to conduct regression analysis consistent with baseline regression, with 164 cities randomly selected as the hypothetical treatment group, while the other 121 cities as the control group. The kernel density distribution of urban haze pollution was illustrated in Fig. 3. As we can see, almost all the absolute values of $t$ values of the sampling estimation coefficients are less than 2 and their corresponding $\mathrm{p}$ values are above 0.1 , indicating that SCP has no significant effect in these 1000 times random sampling. That is, unobserved factors have a negligible impact on the estimated results. Hence, the placebo test is also satisfied.

\section{Heterogeneity Analysis}

As mentioned above, there exists huge heterogeneity among cities with different administrative ranks or in different regions [22, 30]. Following the geographical

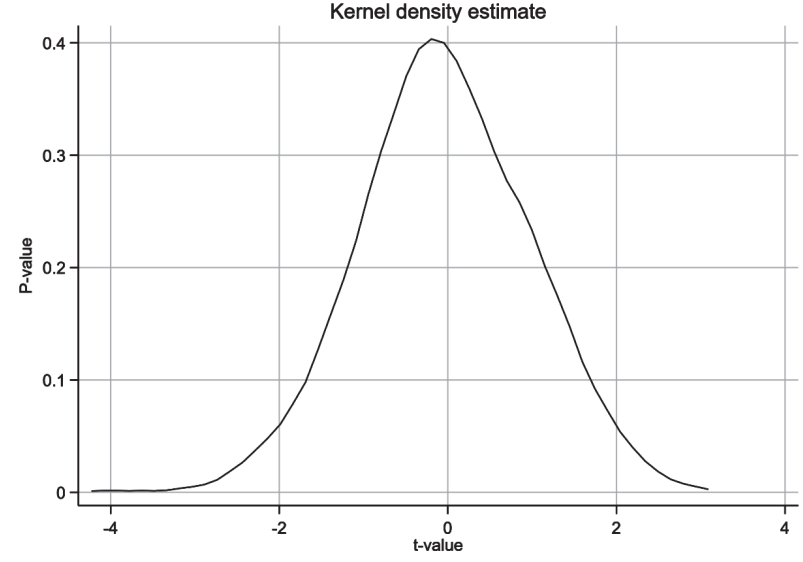

Fig. 3. Placebo test.

division standard announced by the Chinese National Bureau of Statistical (CNBS), the sample cities were firstly classified into three regions, namely, cities of eastern, central, and western China. Then the estimation was conducted based on Eq.(1), and the heterogeneous results of the average effect at the regional level were reported in Table 3 .

As shown in Table 3 , the coefficients $d_{u} \times d_{t}$ are significantly negative in columns (1)-(6), implying that SCP can effectively reduce urban haze pollution at the regional level, no matter with or without the consideration of control variables. Moreover, the absolute value of the coefficient of $d_{u} \times d_{t}$ is the greatest in the western region, followed by the central region, while the eastern region has the least coefficient, thereby confirming the presence of spatial heterogeneity of the intensity of the pollution mitigation effect at the regional level.

To delve into the heterogeneous effects of SCP on urban haze pollution at the city administrative rank level, this study divided the study samples into two parts: first- and second-tier cities and third-tier cities. Specifically, the first- and second-tier cities involve centrally administrated municipalities, provincial capitals and sub-provincial cities, while the third-tier cities are all prefecture-level cities. Regression analysis was performed based on Eq.(1) after the aforementioned classification, and the empirical results were reported in Table 4.

Table 3. The heterogeneous results of the average effect at the regional level.

\begin{tabular}{|c|c|c|c|c|c|c|}
\hline \multirow{2}{*}{ Variables } & \multicolumn{2}{|c|}{ Eastern } & \multicolumn{2}{c|}{ Central } & \multicolumn{2}{c|}{ Western } \\
\cline { 2 - 7 } & $(1)$ & $(2)$ & $(3)$ & $(4)$ & $(5)$ & $(6)$ \\
\hline$d_{u} \times d_{t}$ & $\begin{array}{c}-5.728^{* * *} \\
(-12.421)\end{array}$ & $\begin{array}{c}-4.067^{* * *} \\
(-8.582)\end{array}$ & $\begin{array}{c}-5.986^{* * *} \\
(-12.347)\end{array}$ & $\begin{array}{r}-5.500^{* * *} \\
(-11.638)\end{array}$ & $\begin{array}{r}-9.137^{* * *} \\
(-14.805)\end{array}$ & $\begin{array}{c}-8.935^{* * *} \\
(-14.004)\end{array}$ \\
\hline Control variable & No & Yes & No & Yes & No & Yes \\
\hline Observations & 1,616 & 1,616 & 1,744 & 1,744 & 1,200 & 1,200 \\
\hline R-squared & 0.092 & 0.247 & 0.085 & 0.214 & 0.163 & 0.201 \\
\hline
\end{tabular}


Table 4 . The heterogeneous results of the average effect at the city administrative rank level.

\begin{tabular}{|c|c|c|c|c|}
\hline \multirow{2}{*}{ Variables } & \multicolumn{2}{|c|}{ First- and second-tier } & $(3)$ & \multicolumn{2}{c|}{ Third-tier } \\
\cline { 2 - 5 } & $(1)$ & $(2)$ & $-6.912^{* * *}$ & $-6.275^{* * *}$ \\
& $-5.554 * * *$ & $(-20.965)$ & $(-19.331)$ \\
\hline$d_{u} \times d_{t}$ & $(-8.180)$ & $-4.661^{* * *}$ & No & Yes \\
\hline Control variable & No & Yes & 4,000 & 4,000 \\
\hline Observations & 560 & 560 & 0.105 & 0.202 \\
\hline R-squared & 0.113 & 0.217 & & \\
\hline
\end{tabular}

As we can see in Table 4, the coefficients $d_{u} \times d_{t}$ are significantly negative in columns (1)-(4), implying that SCP can effectively reduce urban haze pollution, as viewed from different levels of city administration rank, no matter with or without the consideration of control variables. Notably, the absolute value of the coefficient of $d_{u} \times d_{t}$ for the group of first- and second-tier cities is smaller than that for the third-tier cities, implying that there exists a spatial heterogeneity in the strength of the pollution mitigation effect in terms of the city administrative rank.

\section{Further Analysis}

Based on Eq. (4), this study explored the direct and indirect effects of SCP on urban haze pollution in China at national, regional, and city administrative rank levels. The corresponding results of the average effect under the first-order adjacency weight matrix and the spatial squared inverse distance weight matrix were reported in Tables 5 and 6 , respectively.

As shown in Table 5, despite the positive but insignificant coefficient of $d_{u} \times d_{t}$ in column (3), all the other five coefficients of $d_{u} \times d_{t}$ are significantly negative, implying that SCP can reduce haze pollution of smart cities directly when incorporating the spatial spillover effect into model, except for the central region. The results are almost the same with the aforementioned results, confirming the robustness of the pollution mitigation effect of SCP.
Table 5 shows that the spatial coefficients of $W_{T, T} D$ are significantly negative in columns (1)-(3) and (6), positive but insignificant in column (4), negative but insignificant in column (5), indicating that the spatial spillover effect of pollution mitigation brought by SCP on urban haze pollution can be established in pilot cities across the country, cities in eastern and central China, or third-tier cities but not cities in western China or first-and second-tier cities under the first-order adjacency weight matrix.

Meanwhile, the spatial coefficients of $W_{N T, T} D$ are significantly negative in columns (1)-(4) and (6), negative but insignificant in column (5), suggesting that the spatial spillover effect of pollution mitigation caused by SCP on urban haze pollution can be basically established in the non-pilot cities neighboring the pilot cities under the first-order adjacency weight matrix at national, regional, and city administrative rank levels (the first- and second-tier cities are an exception).

On the whole, the direct and indirect effect (pollution mitigation) of SCP on urban haze pollution can be established at national, regional, and city administrative rank levels under the first-order adjacency weight matrix .

As shown in Table 6, although the coefficient of $d_{u} \times d_{t}$ is negative but insignificant in column (2), all the other five coefficients of $d_{u} \times d_{t}$ are significantly negative. This indicates that on the whole SCP can reduce haze pollution of smart cities directly when incorporating the spatial spillover effect into model and

Table 5. The direct and indirect effects under the first-order adjacency weight matrix.

\begin{tabular}{|c|c|c|c|c|c|c|}
\hline \multirow{2}{*}{ Variables } & China & Eastern & Central & Western & First- and second-tier & Third-tier \\
\hline & (1) & (2) & (3) & (4) & (5) & (6) \\
\hline$d_{u} \times d_{t}$ & $\begin{array}{c}-3.696 * * * \\
(-6.131)\end{array}$ & $\begin{array}{c}-1.869^{* *} \\
(-2.116)\end{array}$ & $\begin{array}{c}0.034 \\
(0.032)\end{array}$ & $\begin{array}{c}-10.754 * * * \\
(-9.215)\end{array}$ & $\begin{array}{c}-3.396 * * * \\
(-2.629)\end{array}$ & $\begin{array}{c}-3.931 * * * \\
(-5.714)\end{array}$ \\
\hline$W_{T, T} D$ & $\begin{array}{c}-4.980^{* * * *} \\
(-5.319)\end{array}$ & $\begin{array}{c}-3.592 * * * \\
(-2.595)\end{array}$ & $\begin{array}{c}-10.666 * * * \\
(-6.945)\end{array}$ & $\begin{array}{c}1.347 \\
(0.688)\end{array}$ & $\begin{array}{c}-2.694 \\
(-1.234)\end{array}$ & $\begin{array}{c}-5.009 * * * \\
(-4.761)\end{array}$ \\
\hline$W_{N T, T} D$ & $\begin{array}{c}-9.613 * * * \\
(-17.465)\end{array}$ & $\begin{array}{c}-4.519 * * * \\
(-5.416)\end{array}$ & $\begin{array}{c}-8.698 * * * \\
(-8.929)\end{array}$ & $\begin{array}{c}-15.598^{* * * *} \\
(-15.275)\end{array}$ & $\begin{array}{c}-2.762 \\
(-1.184)\end{array}$ & $\begin{array}{c}-10.031 * * * \\
(-17.536)\end{array}$ \\
\hline Control variable & Yes & Yes & Yes & Yes & Yes & Yes \\
\hline Observations & 4,560 & 1,616 & 1,744 & 1,200 & 560 & 4,000 \\
\hline R-squared & 0.311 & 0.356 & 0.325 & 0.383 & 0.313 & 0.316 \\
\hline
\end{tabular}


Table 6. The direct and indirect effects under the squared inverse distance weight matrix.

\begin{tabular}{|c|c|c|c|c|c|c|}
\hline \multirow{2}{*}{ Variables } & China & Eastern & Central & Western & First- and second-tier & Third-tier \\
\cline { 2 - 7 } & $(1)$ & $(2)$ & $(3)$ & $(4)$ & $(5)$ & $(6)$ \\
\hline \multirow{2}{*}{$d_{u} \times d_{t}$} & $\begin{array}{c}-5.744^{* * *} \\
(-10.625)\end{array}$ & $\begin{array}{c}-1.096 \\
(-1.247)\end{array}$ & $\begin{array}{c}-3.007^{* * *} \\
(-3.246)\end{array}$ & $\begin{array}{c}-12.661^{* * *} \\
(-13.139)\end{array}$ & $\begin{array}{c}-3.243^{* *} \\
(-2.485)\end{array}$ & $\begin{array}{c}-6.191 * * * \\
(-10.387)\end{array}$ \\
\hline$W_{T, T} D$ & $\begin{array}{c}-1.073 \\
(-1.385)\end{array}$ & $\begin{array}{c}-3.232^{* * *} \\
(-2.606)\end{array}$ & $\begin{array}{c}-5.077^{* * *} \\
(-4.016)\end{array}$ & $\begin{array}{c}5.133^{* * *} \\
(3.509)\end{array}$ & $\begin{array}{c}-1.626 \\
-0.898)\end{array}$ & $\begin{array}{c}-0.938 \\
(-1.087)\end{array}$ \\
\hline$W_{N T, T} D$ & $-8.212^{* * *}$ & $\begin{array}{c}-3.369^{* * *} \\
(-16.367)\end{array}$ & $\begin{array}{c}-6.741^{* * *} \\
(-7.283)\end{array}$ & $\begin{array}{c}-14.384 * * * \\
(-14.757)\end{array}$ & $\begin{array}{c}-3.936^{*} \\
(-1.759)\end{array}$ & $\begin{array}{c}-8.555^{* * *} \\
(-16.597)\end{array}$ \\
\hline Control variable & Yes & Yes & Yes & Yes & Yes & Yes \\
\hline Observations & 4,560 & 1,616 & 1,744 & 1,200 & 560 & 4,000 \\
\hline R-squared & 0.288 & 0.344 & 0.304 & 0.366 & 0.313 & 0.291 \\
\hline
\end{tabular}

analyzing under the squared inverse distance weight matrix at national, regional, and city administrative rank levels, except for the eastern region.

The spatial coefficients of $W_{T, T} D$ are significantly negative in columns (2)-(3), significantly positive in column (4), negative but insignificant in column (1), (5), and (6) (see Table 6). The results suggest that the spatial spillover effect of pollution mitigation caused by SCP on urban haze pollution can be established in pilot cities in eastern and central China under the squared inverse distance weight matrix. However, the spatial spillover effect of the implementation of SCP aggravated the haze pollution of the pilot cities in western China under the squared inverse distance weight matrix, thereby verifying the presence of "beggar-thy-neighbor" effect.

It is worth noting that the spatial coefficients of $W_{N T, T} D$ are significantly negative in columns (1)-(6), indicating that the spatial spillover effect of pollution mitigation caused by SCP on urban haze pollution can be established in the non-pilot cities neighboring the pilot cities under the squared inverse distance at national, regional, and city administrative rank levels. This result confirms the presence of the "demonstration effect" of SCP on haze pollution mitigation of the nonpilot cities.

Overall, the direct and indirect effect (pollution mitigation) of SCP on urban haze pollution can be established at national, regional, and city administrative rank levels under the squared inverse distance weight matrix. However, the implementation of SCP in one city can aggravate the haze pollution of other smart cities in western China. This "beggar-thy-neighbor" effect deserves further attention.

Through the above analysis, it can be seen that, in general, SCP reduced urban haze pollution of pilot cities. Moreover, there exists spatial heterogeneity in the intensity of the pollution mitigation effect at regional and city administrative rank levels. In addition, this study identifies the spatial spillover effect of SCP.
The implementation of SCP has spatial spillover effects on the neighboring pilot cities and non-pilot cities, but the spatial spillover effects also show spatial heterogeneity. The research findings show that smart city, as a new mode of city development, could exert an important influence on haze pollution reduction. This study provides empirical support for the argument that smart cities could be the ideal solution to the environmental challenges of rapid urbanization [15] and, hence, echoes the recent studies that have investigated the environmental effects of SCP $[1,17$, 20].

Different from previous studies, this study directly focuses on the impact of SCP on urban haze pollution, adequately explore the heterogeneity of pollution reduction effect of $\mathrm{SCP}$, and identifies the spatial spillover effect of SCP on the basis of DID and SDID models. This indicates that a novel spatial econometric perspective is more reasonable and, hence, should be advocated when it comes to the policy effect evaluation of SCP. Moreover, the effects of SCP on urban haze pollution can be different by adopting different spatial weight matrices, and hence great attention should be paid to the selection of appropriate spatial weigh matrix.

\section{Limitations of Research}

Although this study has initially introduced the SDID model to investigate the effects of SCP on urban haze pollution in China, several potential limitations still deserve in-depth exploration. For instance, due to the limitation of data, only $\mathrm{PM}_{2.5}$ was used as the proxy indicator of air pollution, future studies can incorporate other air pollutants (e.g., $\mathrm{SO}_{2}, \mathrm{NO}_{2}, \mathrm{O}_{3}$, and $\mathrm{CO}$ ) into the measurement of urban haze pollution. Additionally, due to the limitation of technological availability, the temporal/dynamic effect was ignored in the empirical analysis, further research can be employed to clarify this effect in the future. 


\section{Conclusions}

Reducing haze pollution should be a theme of smart city construction, while little attention has been paid to the pollution reduction effect of SCP. To fill this gap, this study empirically investigated the effect of SCP on urban haze pollution in China. The main conclusions of this study can be drawn as three points.

First, SCP has basically reduced urban haze pollution at national, regional, and city administrative rank levels without the consideration of spatial spillover effects, while there exists a five-year lag at the national level. Second, on the basis of the SDID model, the coexistence of the "beggar-thy-neighbor" effect and the "demonstration effect" of SCP on urban haze pollution in China are confirmed under the squared inverse distance weight matrix at the regional level. Last but not least, the spatial heterogeneity of SCP on urban haze pollution in China is identified at regional and city administrative rank levels.

From a managerial perspective, our findings yield several policy implications. First, the implementation of SCP helps to balance city construction (economic development) and environmental protection. Thus, both central and local governments should incorporate smart city construction into their economic and social development plans and vigorously support the smart city initiatives. This is particularly important when considering the fact that smart cities in China are still in the initial stage and there is a great distance from the real intelligence [17]. The smart cities in China still have great potential to reduce haze pollution. Second, smart city construction is an important way for economically underdeveloped areas to catch up and surpass. This is true because currently smart cities in the central and western regions have advantages over those in the eastern region in reducing haze pollution. Moreover, third-tier smart cities have advantages over first- and second-tier smart cities. Third, the spatial spillover effect of SCP on urban haze pollution deserves more attention, the "beggar-thyneighbor" effect in particular. The traditional viewpoint of "beggar-thy-neighbor" should be replaced by the notion of green development with the establishment of a benefit-responsibility sharing mechanism in the process of smart city construction. However, this is inseparable from the top-level design of the central government and still has a long way to go. Finally, considering the spatial heterogeneity of SCP on urban haze pollution, a national framework for joint governance of urban haze pollution should be established coupled with the implementation of SCP. Meanwhile, city resource endowment should be taken into account and differentiated policies can be implemented to give full play to the advantages of various cities. It is extremely critical to avoid "one size fits all" in the process of top-level design of SCP.

\section{Acknowledgments}

This work was supported by the China Association for Science and Technology High-end Science and Technology Innovation Think Tank Doctoral Program (Grant No. CXY-ZKQN-2019-002). The authors would also like to thank the anonymous reviewers and editors for their constructive comments and advice.

\section{Conflict of Interest}

The authors declare no conflict of interest.

\section{References}

1. XIN B.G., QU Y.M. Effects of smart city policies on green total factor productivity: Evidence from a quasi-natural experiment in China. Int. J. Env. Res. Pub. He. 16 (13), 2396, 2019.

2. GU S. Transformation and healthy development of urbanization in China's $13^{\text {th }}$ five-year national development period (2016-2020). In China's Urbanization and Socioeconomic Impact. Springer, Singapore, 2017.

3. SHEN L.Y., HUANG Z.H., WONG S.W., LIAO S.J., LOU Y.L. A holistic evaluation of smart city performance in the context of China. J. Clean. Prod. 200, 667, 2018.

4. FARRIS J.T. The barriers to using urban infill development to achieve smart growth. Hous. Policy Debate. 12 (1), 1, 2001.

5. HEINS M. Finding common ground between new urbanism and landscape urbanism. J. Urban Des. 20 (3), 293, 2015.

6. APPIO F.P., LIMA M., PAROUTIS S. Understanding smart cities: Innovation ecosystems, technological advancements, and societal challenges. Technol. Forecast. Soc. 142, 1, 2019.

7. YANG F., XU J. Privacy concerns in China's smart city campaign: The deficit of China's Cybersecurity Law. Asia Pac. Policy Stu. 5 (3), 533, 2018.

8. HAARSTAD H., WATHNE M.W. Are smart city projects catalyzing urban energy sustainability? Energ. Policy 129, 918, 2019.

9. GUO Y., TANG Z., GUO J. Could a smart city ameliorate urban traffic congestion? A quasi-natural experiment based on a smart city pilot program in China. Sustainability, 12 (6), 2291, 2020.

10. LV Z.H., LI X.M., WANG W.X., ZHANG B.Y., HU J.X., PENG S.Z. Government affairs service platform for smart city. Future Gener. Comp. Sy. 81, 443, 2018.

11. ZHANG N., ZHAO X.J., HE X.P. Understanding the relationships between information architectures and business models: An empirical study on the success configurations of smart communities. Gov. Inform. Q. 37 (2), 101439, 2020.

12. YAN J.H., LIU J.P., TSENG F.M. An evaluation system based on the self-organizing system framework of smart cities: A case study of smart transportation systems in China. Technol. Forecast. Soc. 153, 119371, 2020.

13. YU Y.T., ZHANG N. Does smart city policy improve energy efficiency? Evidence from a quasi-natural experiment in China. J. Clean. Prod. 229, 501, 2019. 
14. ROSCIA M., LONGO M., LAZAROIU G.C. Smart city by multi-agent systems. In 2013 International Conference on Renewable Energy Research and Applications (ICRERA), IEEE. 371, 2013.

15. DATTA A. New urban utopias of postcolonial India. Dial. Hum. Geogr. 5 (1), 3, 2015.

16. VERREST H., PFEFFER K. Elaborating the urbanism in smart urbanism: Distilling relevant dimensions for a comprehensive analysis of Smart City approaches. Inform. Commun. Soc. 22 (9), 1328, 2019.

17. YAO T., HUANG Z., ZHAO W. Are smart cities more ecologically efficient? Evidence from China. Sustain. Cities Soc. 60, 102008, 2020.

18. XU N., DING Y., GUO J. Do smart city policies make cities more innovative: Evidence from China. J. Asian Public Policy. 1, 2020.

19. QIAN Y., LIU J., CHENG Z., JEFFREY Y.F. Does the smart city policy promote the green growth of the urban economy? Evidence from China. Environ. Sci. Pollut. Res. 2021.

20. LI L., ZHENG Y., ZHENG S., KE H. The new smart city programme: Evaluating the effect of the internet of energy on air quality in China. Sci. Total Environ. 714, 136380, 2020.

21. WU H.T., LI Y.W., HAO Y., REN S.Y., ZHANG P.F. Environmental decentralization, local government competition, and regional green development: Evidence from China. Sci. Total Environ. 708, 135085, 2020.

22. HU Q., ZHENG Y.P. Smart city initiatives: A comparative study of American and Chinese cities. J. Urban Aff. 43 (4), $1,2020$.

23. DAMERI R.P., BENEVOLO C., VEGLIANTI E., LI Y. Understanding smart cities as a global strategy:
A comparison between Italy and China. Technol. Forecast. Soc. 142, 26, 2019.

24. HAMMER M.S., VAN DONKELAAR A., LI C., LYAPUSTIN A., SAYER A.M., HSU N.C., LEVY R.C., GARAY M.J., KALASHNIKOVA O.V., KAHN R.A., BRAUER M., APTE J.S., HENZE D.K., ZHANG L., ZHANG Q., FORD,B., PIERCE J.R., MARTIN R.V. Global estimates and long-term trends of fine particulate matter concentrations (1998-2018). Environ. Sci. Technol, 54 (13), 7879, 2020.

25. VAN DONKELAAR A., MARTIN R.V., LI C., BURNETT R.T. Regional estimates of chemical composition of fine particulate matter using a combined geoscience-statistical method with information from satellites, models, and monitors. Environ. Sci. Technol, 53 (5), 2595, 2019.

26. GAN T., LIANG W., YANG H., LIAO X. The effect of economic development on haze pollution $\left(\mathrm{PM}_{2.5}\right)$ based on a spatial perspective: Urbanization as a mediating variable. J. Clean. Prod. 266, 121880, 2020.

27. WU J., ZHANG P., YI H., QIN Z.What causes haze pollution? An empirical study of $\mathrm{PM}_{25}$ concentrations in Chinese cities. Sustainability, 8 (2), 132, 2016.

28. CHAGAS A.L.S., AZZONI C.R., ALMEIDA A.N. A spatial difference-in-differences analysis of the impact of sugarcane production on respiratory diseases. Reg. Sci. Urb. Eco. 59, 24, 2016.

29. YI L., BAI N., YANG L., LI Z., WANG F. Evaluation on the effectiveness of China's pilot carbon market policy. J. Clean. Prod. 246, 119039, 2020.

30. ZHUANG L., YE C. Changing imbalance: Spatial production of national high-tech industrial development zones in China (1988-2018). Land use policy. 94, 104512, 2020. 